\title{
An alternative causal link between peptide fibrillization and $\beta$-strand conformation
}

Zhihua Xing ${ }^{\dagger, \star}$, Yongzhu Chen ${ }^{\dagger, \S}$, Feng Qiu ${ }^{\dagger, \triangle, *}$

$\dagger$ Laboratory of Anesthesia and Critical Care Medicine, Translational Neuroscience

Center and National Clinical Research Center for Geriatrics, West China Hospital,

Sichuan University, Chengdu, 610041, China

¥ Laboratory of Ethnopharmacology, West China Hospital, Sichuan University,

Chengdu, 610041, China.

$\S$ Periodical Press of West China Hospital, Sichuan University, Chengdu, 610041, China

$\triangle$ National-Local Joint Engineering Research Center of Translational Medicine of Anesthesiology, West China Hospital, Sichuan University, Chengdu, 610041, China

\section{Corresponding Author}

*Feng Qiu, E-mail: fengqiu@scu.edu.cn 


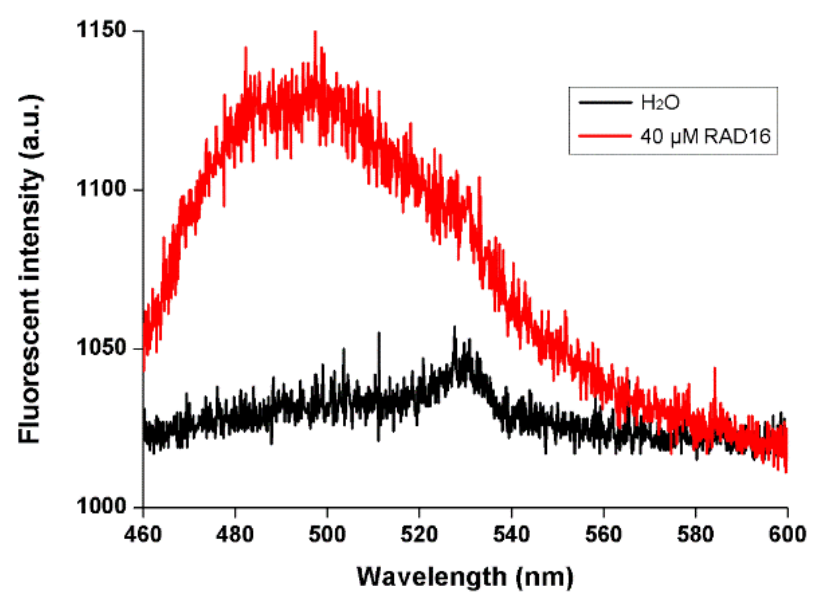

Figure S1. ThT-binding fluorescent spectrum of $40 \mu \mathrm{M}$ RADA16-I compared with $\mathrm{H}_{2} \mathrm{O}$.

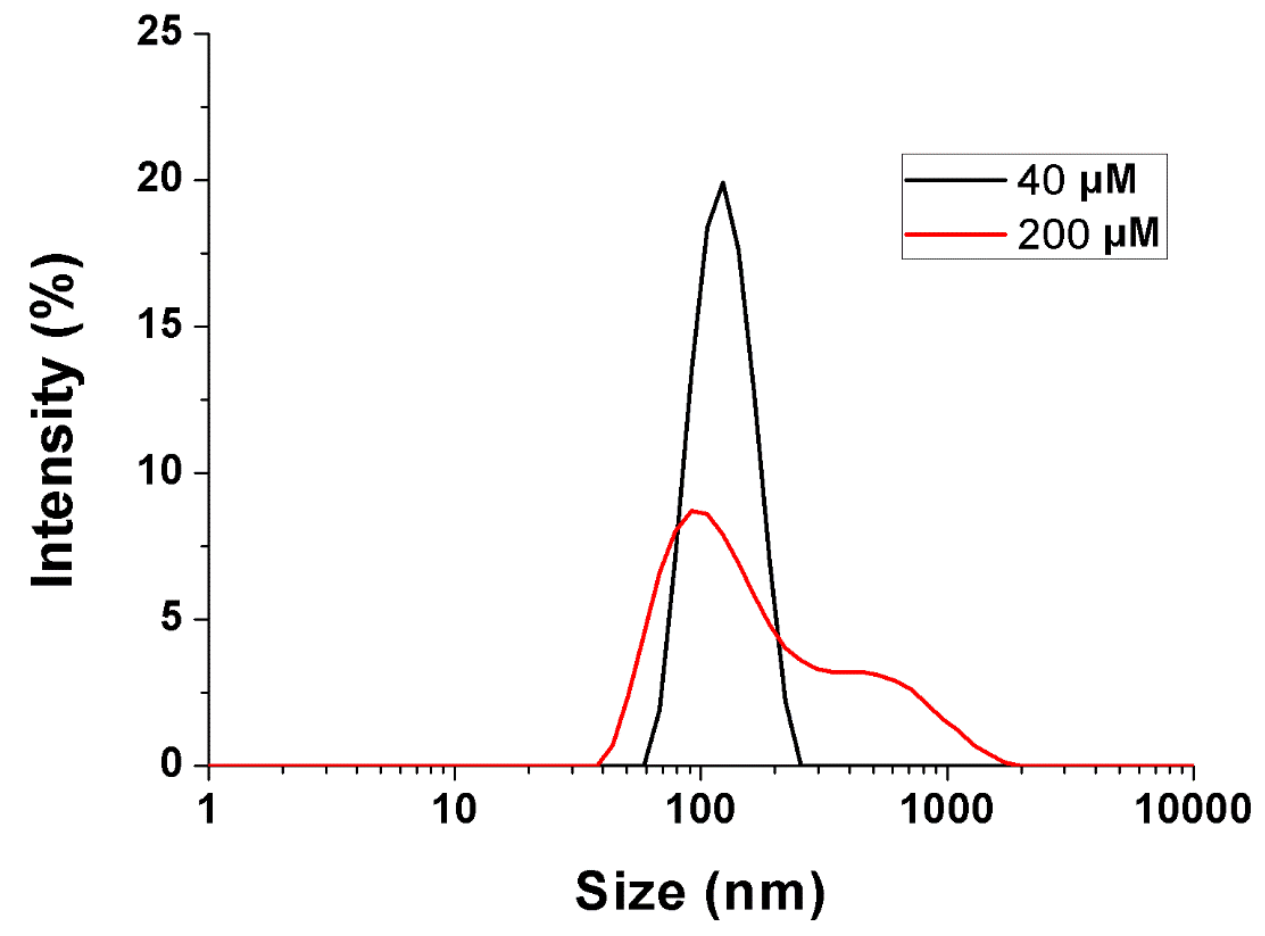

Figure S2. Size distribution of $40 \mu \mathrm{M}$ and $200 \mu \mathrm{M}$ RADA16-1 revealed by DLS. 

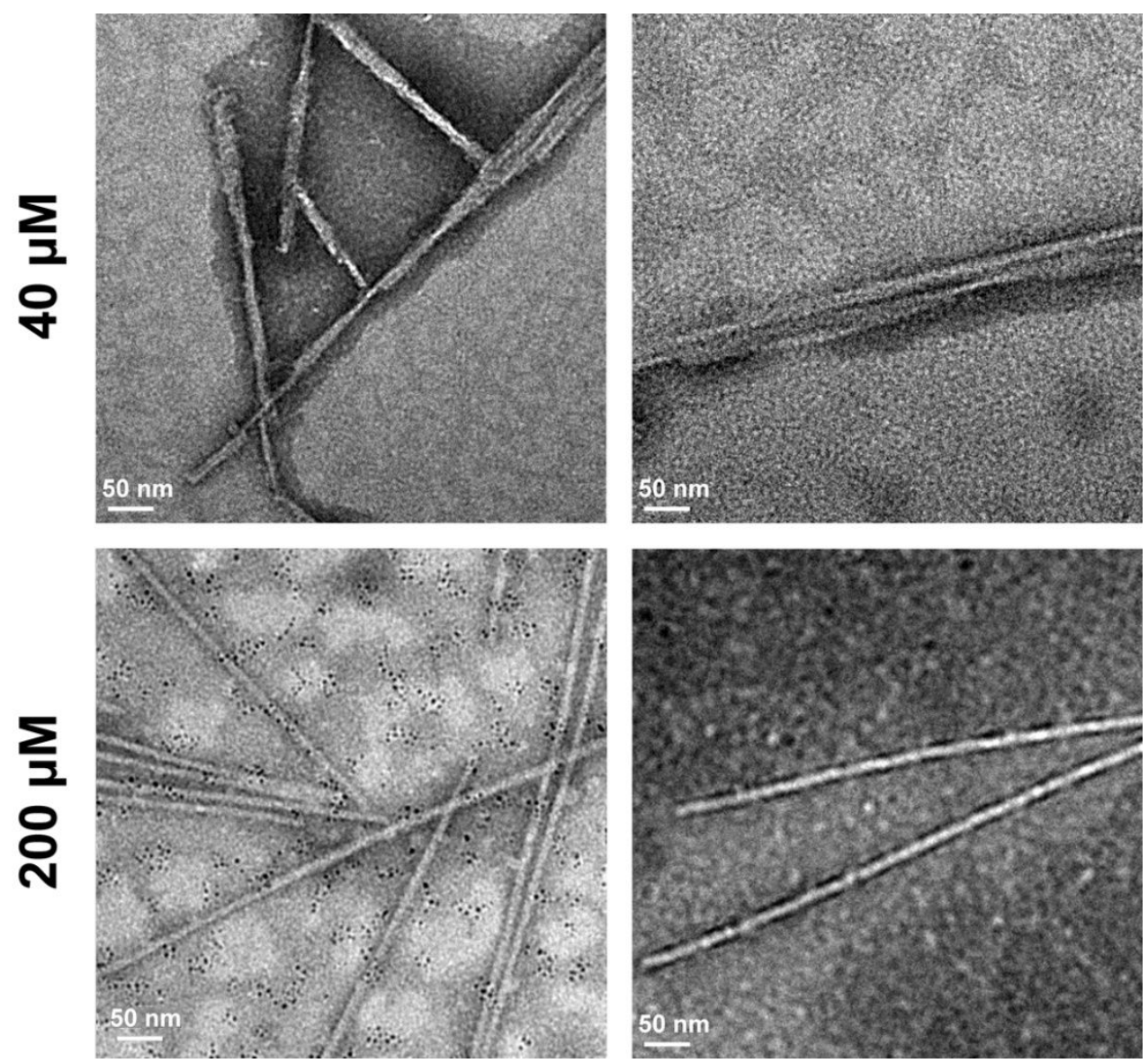

Figure S3. Additional TEM images of nanofibers formed by $40 \mu \mathrm{M}$ and $200 \mu \mathrm{M}$ RADA16-1.

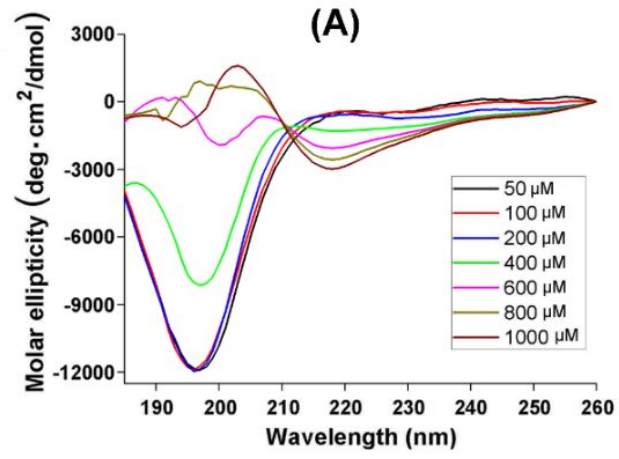

(C)

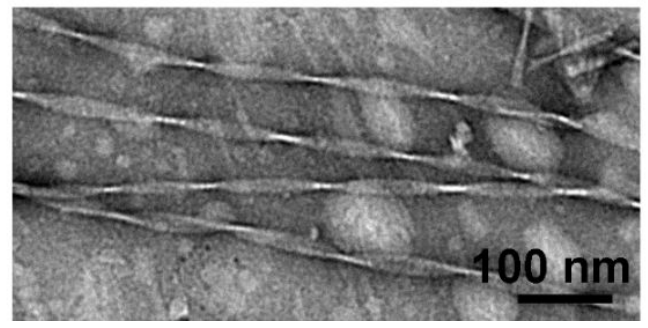

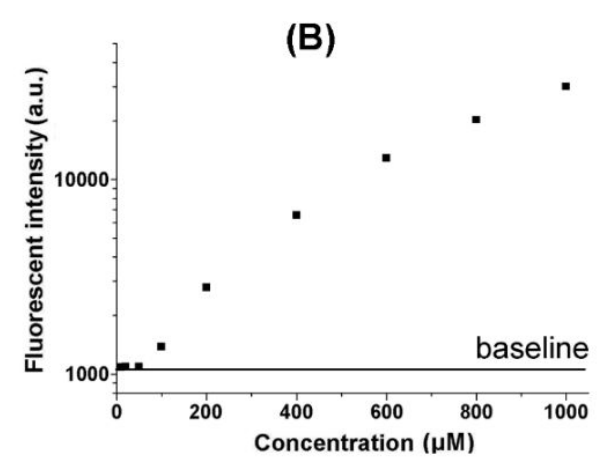

(D)

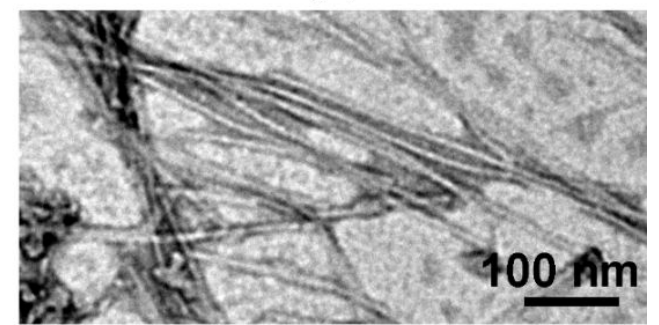


Figure S4. Concentration determined secondary structure and fibrillization state of DA6D. (A) CD spectra showed that the peptide took disordered conformation at lower concentration and began to transform to $\beta$-strand conformation at $400 \mu \mathrm{M}$. It should be noted that although at higher concentrations over $600 \mu \mathrm{M}$, CD signals below $200 \mathrm{~nm}$ were interfered by very high background noise, the negative signals around $220 \mathrm{~nm}$ were still reliable to show the formation of $\beta$-strand. (B) ThT-binding fluorescence showed that the peptide began to aggregate at $100 \mu \mathrm{M}$. (C) TEM image of helix ribbons formed at $100 \mu \mathrm{M}$. (D) TEM image of smooth nanofibers formed at $1000 \mu \mathrm{M}$.
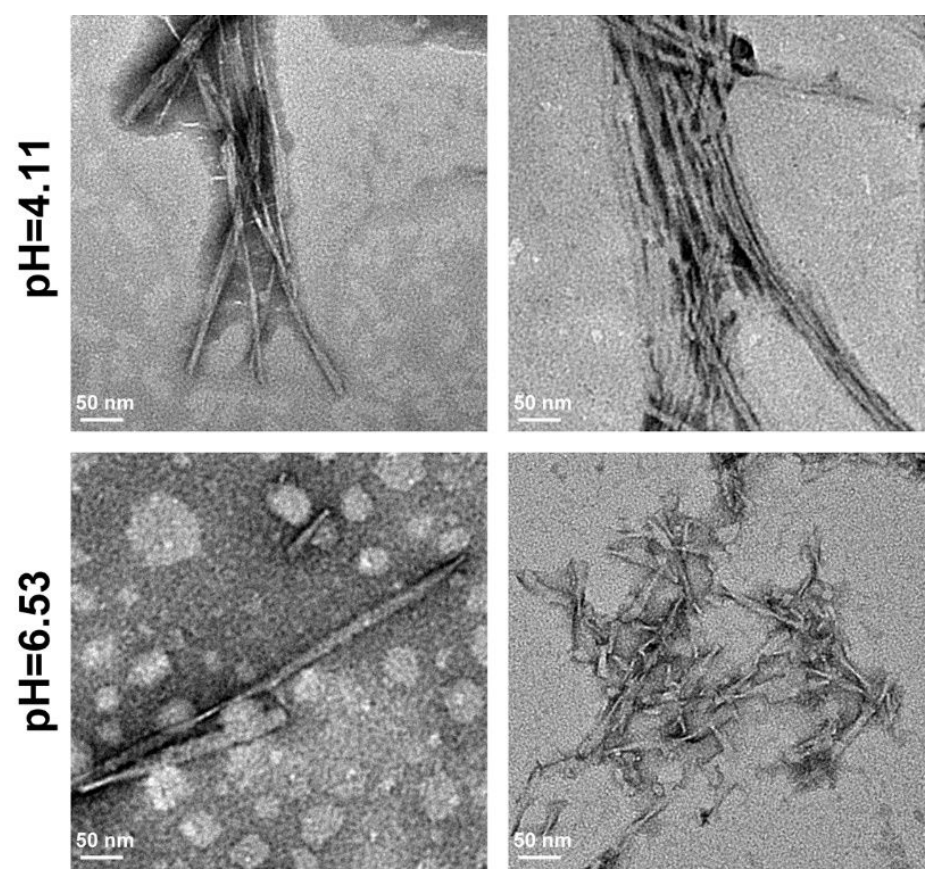

Figure S5. Additional TEM images of nanofibers formed by $200 \mu \mathrm{M}$ RADA16-1 at pH 4.11 or 6.53 . 


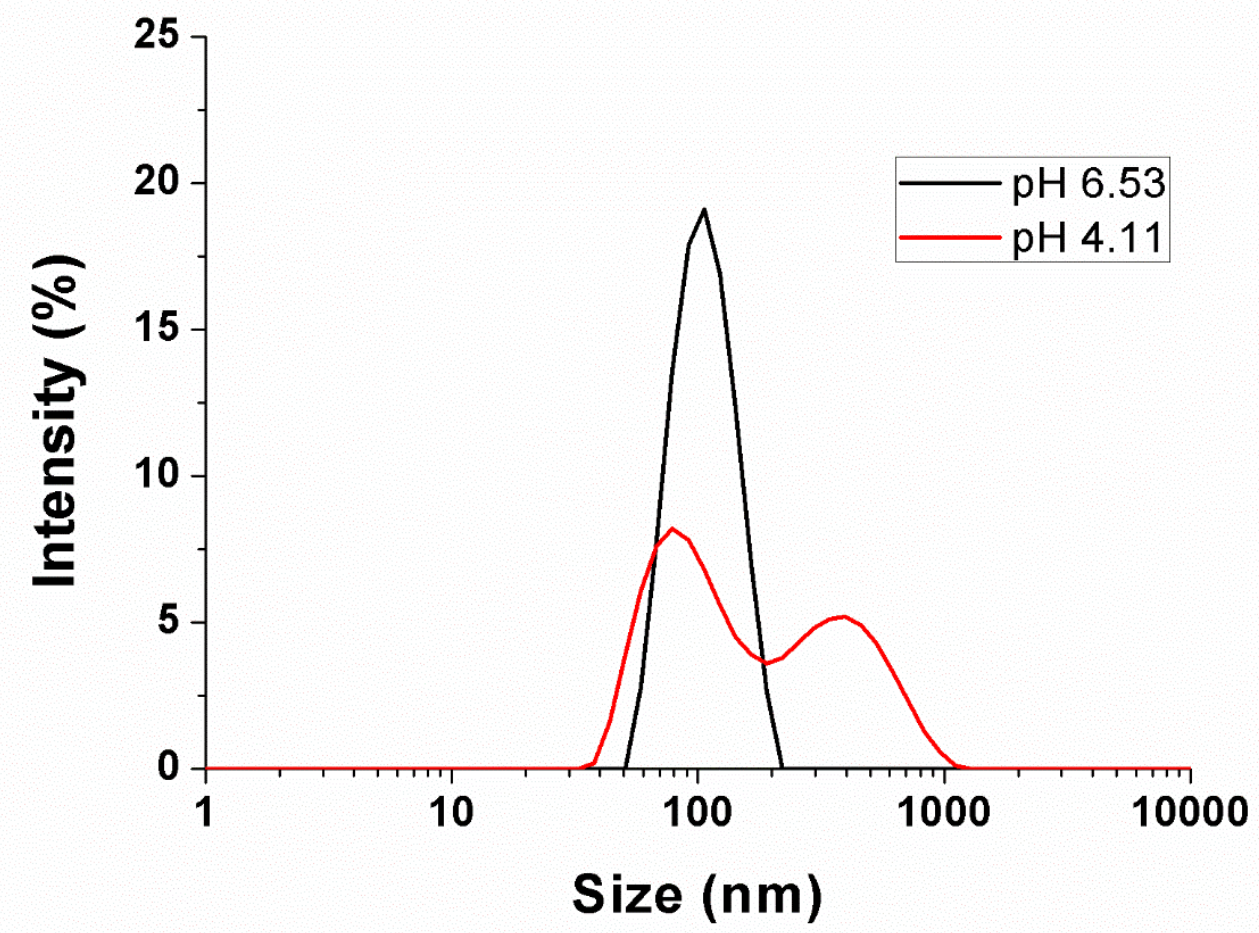

Figure S6. Size distribution of $200 \mu \mathrm{M}$ RADA16-1 at pH 4.11 or 6.53 .

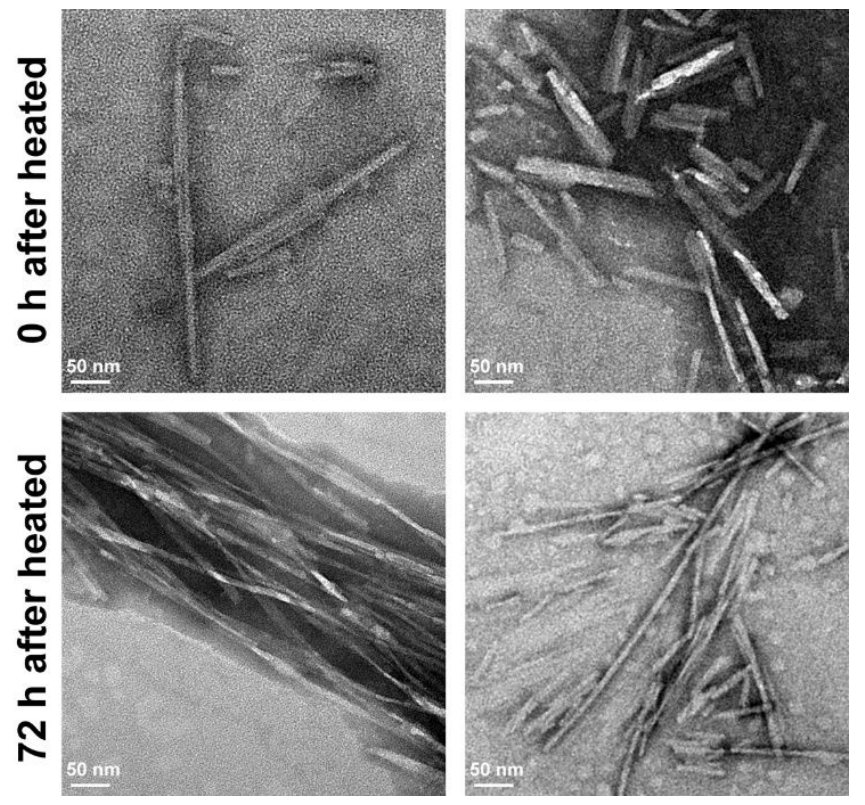

Figure S7. Additional TEM images of nanofibers formed by $200 \mu \mathrm{M}$ RADA16-1 $0 \mathrm{~h}$ or $72 \mathrm{~h}$ after heated. 


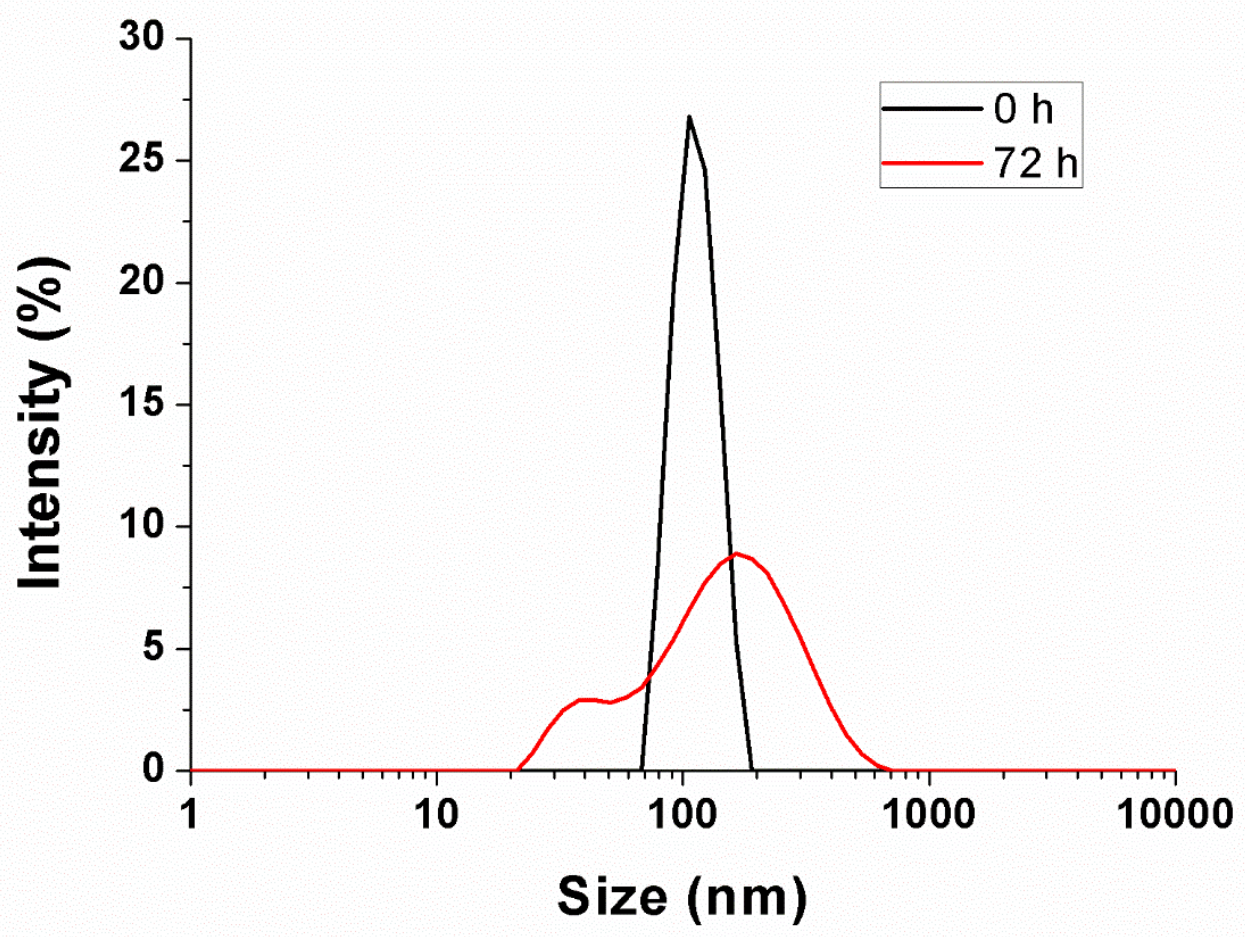

Figure S8. Size distribution of $200 \mu \mathrm{M}$ RADA16-1 $0 \mathrm{~h}$ or $72 \mathrm{~h}$ after heated. 